\title{
Peri-operative ketamine with the ambulatory elastometric infusion pump as an adjuvant to manage acute postoperative pain after spinal fusion in adults: a prospective randomized trial
}

Jong Hoon Yeom, Myong-Su Chon, Woo Jae Jeon, and Jae-Hang Shim

Department of Anesthesiology and Pain Medicine, Hanyang University Guri Hospital, Guri, Korea

Background: In this study, we assessed the effectiveness of ketamine as an alternative to non-steroidal antiinflammatory drugs (NSAID), to manage acute postoperative pain after spinal fusion when given intravenously via a patient-controlled analgesia (PCA) pump in which the dose was proportional to that of fentanyl.

Methods: Forty patients undergoing 1-2 level spinal fusion were enrolled in this study. Patients were intraoperatively randomized into two groups to receive intravenous PCA consisting either of fentanyl $0.4 \mu \mathrm{g} / \mathrm{ml} / \mathrm{kg}$ (control group) or fentanyl $0.4 \mu \mathrm{g} / \mathrm{ml} / \mathrm{kg}$ with ketamine $30 \mu \mathrm{g} / \mathrm{ml} / \mathrm{kg}$ (ketamine group) after intravenous injection of a loading dose. The loading dose in the control group was fentanyl $1 \mu \mathrm{g} / \mathrm{kg}$ with normal saline equal to ketamine volume and in the ketamine group it was fentanyl $1 \mu \mathrm{g} / \mathrm{kg}$ with ketamine $0.2 \mathrm{mg} / \mathrm{kg}$. The verbal numerical rating scale (NRS), fentanyl and ketamine infusion rate, and side effects were evaluated at 1, 24, and 48 hours after surgery.

Results: There were no significant differences in patient demographics, duration of surgery and anesthesia or intra-operative opioids administration. We did not find any significant differences in the mean infusion rate of intraoperative remifentanil or postoperative fentanyl or in the side effects between the groups, but we did find a significant difference in the NRS between the groups.

Conclusions: Based on our results, we conclude that a small dose of ketamine $(0.5-2.5 \mu \mathrm{g} / \mathrm{kg} / \mathrm{min})$ proportional to fentanyl is not only safe, but also lowers postoperative pain intensity in patients undergoing spinal fusion, although the opioid-sparing effects of ketamine were not demonstrated. (Korean J Anesthesiol 2012; 63: 54-58)

Key Words: Fentanyl, Ketamine, Patient-controlled analgesia, Spinal fusion.

Received: July 19, 2011. Revised: 1st, October 4, 2011; 2nd, December 23, 2011. Accepted: December 26, 2011.

Corresponding author: Jong Hoon Yeom, M.D., Department of Anesthesiology and Pain Medicine, Hanyang University Guri Hospital, 249-1, Kyomun-dong, Guri 471-701, Korea. Tel: 82-31-560-2390, Fax: 82-31-563-1731, E-mail: yeomjh@hanyang.ac.kr

(c) This is an open-access article distributed under the terms of the Creative Commons Attribution Non-Commercial License (http:// creativecommons.org/licenses/by-nc/3.0/), which permits unrestricted non-commercial use, distribution, and reproduction in any medium, provided the original work is properly cited. 


\section{Introduction}

After spinal fusion surgery patients experience considerable pain that is typically initially treated with intravenous narcotics only, but due to its multiple side effects, 'balanced analgesia' is more frequently recommended nowadays. Balanced analgesia consists of analgesic drugs acting on different systems to alleviate postoperative pain. A combination of drugs allows the use of a lower dose of each component while achieving a safer and more reliable analgesic effect. For the aforementioned reasons, opiates, non-steroidal anti-inflammatory drugs (NSAIDs), local anesthetics, and $\alpha_{2}$-adrenoceptor agonists are currently most commonly used with postoperative pain management [1] .

In certain surgeries such as spinal fusions, the use of NSAIDs for the management of acute postoperative pain is not recommended by some surgeons because it may have a negative influence on the surgical outcome [2-4]. That is why we considered ketamine as an alternative to NSAIDs as a component of balanced analgesia for spinal fusion. Even though the role of ketamine in the management of acute postoperative pain remains controversial $[5,6]$, recent studies suggest that low dose ketamine (defined as a bolus dose of less than $2 \mathrm{mg} / \mathrm{kg}$ when given intramuscularly or less than $1 \mathrm{mg} / \mathrm{kg}$ when administered via intravenous or epidural route) as an adjuvant to opioids or local anesthetics may have an important role in the treatment of acute postoperative pain [7-9] .

We attempted to assess the analgesic effectiveness of low dose ketamine as an alternative to NSAIDs for the management of acute postoperative pain after spinal fusion when given intravenously via a PCA pump (Accufuser PLUS ${ }_{\mathrm{REF}}{ }^{\circledR}$, Woo Young Med., Korea), in which the dose was proportional to that of fentanyl.

\section{Materials and Methods}

Forty patients between the ages of $38-78$ years undergoing 1-2 level posterior lumbar spinal fusion were enrolled in this study. All of the patients were American Society of Anesthesiologists physical status classification 1, 2, or 3. Patients with a body mass indexes (BMI) $\geq 30$ were excluded from the study.

We received the approval of the Human Subjects' Ethical Committee and all participants of this study provided written informed consent. The day before surgery, patients were taught how to use the verbal numerical rating scale (NRS) (0 was defined as no pain and 10 was defined as the worst pain ever experienced by the patient), and the PCA pump. The patients were also instructed to self-deliver analgesia by pressing the bolus button at any time if they began to feel unendurable pain. The PCA pump used in this study was the ambulatory elastometric infusion pump (total volume $100 \mathrm{ml}$, basal flow rate; $1.0 \mathrm{ml} / \mathrm{h}$, bolus volume; $1.0 \mathrm{ml} /$ time, lockout time; $15 \mathrm{~min}$ ).

Enrolled patients were not premedicated and each of them received general balanced anesthesia with sevoflurane- $\mathrm{N}_{2} \mathrm{O}$ oxygen and continuous infusion of remifentanil. Tracheal intubation was performed under thiopental sodium $4-5 \mathrm{mg} /$ $\mathrm{kg}$, rocuronium $0.6-0.7 \mathrm{mg} / \mathrm{kg}$ and sevoflurane inhalation.

The patients were randomly allocated into two groups in a double-blind manner. To provide patients with a continuous fentanyl dose in the range of $0.4-2.0 \mu \mathrm{g} / \mathrm{kg} / \mathrm{h}$ and a ketamine dose in the range of $0.5-2.5 \mu \mathrm{g} / \mathrm{kg} / \mathrm{min}$, the PCA pump was used to intravenously infuse fentanyl at a dose of $0.4 \mu \mathrm{g} / \mathrm{kg} / \mathrm{ml}$ for the control group, and fentanyl and ketamine at a dose of $0.4 \mu \mathrm{g} / \mathrm{kg} /$ $\mathrm{ml}$ and $30 \mu \mathrm{g} / \mathrm{kg} / \mathrm{ml}$, respectively, for the ketamine group after an intravenous injection of a loading dose. The loading dose in the control group was fentanyl $1 \mu \mathrm{g} / \mathrm{kg}$ with normal saline (total volume same as ketamine group) and in the ketamine group it was fentanyl $1 \mu \mathrm{g} / \mathrm{kg}$ with ketamine $0.2 \mathrm{mg} / \mathrm{kg}$. In our study the loading dose was intra-operatively administered within 1 hour after the incision to avoid strong postoperative residual effect of opioids. Ramosetron was administered to all patients before wound closure to prevent postoperative nausea and vomiting (PONV). After surgery, patients were observed at the post anesthesia care unit (PACU) for at least 60 minutes. After the patients regained adequate cognitive function, they were returned to the general ward with the PCA pumps fully operational. No supplemental analgesia or sedation was administered for the 48 hours immediately after surgery. Ondansetron $0.1 \mathrm{mg} / \mathrm{kg}$ was given intravenously for nausea or vomiting as required. The infused volume through the PCA pump during the first 1 hour was estimated by summing the amount of basal flow rate $(1.0 \mathrm{ml} / \mathrm{h})$ plus the total amount of infused bolus volume $(1.0 \mathrm{ml}$ for each time the bolus button was pressed), and the remaining amount indicated in the scale attached to the PCA pump 1 hour after the surgery was checked. The total amount infused at 24 hours after surgery (remaining PCA volume at 1 hour after surgery minus remaining PCA volume at 24 hours after surgery) and 48 hours after surgery (remaining PCA volume at 24 hours after surgery minus remaining PCA volume at 48 hours after surgery) was checked, and all other data including NRS were collected at the same time. Remifentanil requirements were computed by dividing the total dose administered by the duration of anesthesia (h) and body weight $(\mathrm{kg})$. Ketamine requirements were computed by dividing the total dose administered by duration (min) and body weight $(\mathrm{kg})$. Also, fentanyl requirements were computed by dividing the total dose administered by duration (h) and body weight $(\mathrm{kg})$. Side effects such as nausea/vomiting and pruritis occurred during each postoperative period were 
collected at 1, 24, and 48 hours after surgery.

To eliminate possible bias, all the PCA related drugs (basal and loading dose for the control and ketamine group) were prepared by blinded anesthesiologists who were not involved in this study. Also, all members involved in this study (enrolled patients, anesthesiologist who delivered the PCA and evaluated analgesic effect) were blinded to the solutions they used or evaluated. Thus, the study was performed in a double blinded manner.

Based on a pilot study we estimated the sample size to detect a difference of 2 in NRS pain score with mean $( \pm$ SD) difference between the groups, with a power of $80 \%, \alpha=0.05$, and drop rate $=0.1$. The estimated sample size by power analysis was 15 patients per group. Statistical analyses of data were performed using GraphPad Prism (Version 3.02, USA). Analysis of sex, side effects and physical status were conducted using the Fisher's exact test. Analysis of NRS was conducted using the

Table 1. Patient Demographics Data in this Study

\begin{tabular}{lcc}
\hline & $\begin{array}{c}\text { Control } \\
(\mathrm{n}=20)\end{array}$ & $\begin{array}{c}\text { Ketamine } \\
(\mathrm{n}=20)\end{array}$ \\
\hline Sex $(\mathrm{M} / \mathrm{F})$ & $7 / 13$ & $5 / 15$ \\
Age $(\mathrm{yr})$ & $64.5 \pm 11.5$ & $61.0 \pm 10.0$ \\
Weight $(\mathrm{kg})$ & $64.8 \pm 10.6$ & $59.1 \pm 13.5$ \\
Height $(\mathrm{cm})$ & $158.5 \pm 8.9$ & $155.6 \pm 9.5$ \\
ASA status $(1: 2: 3)$ & $6 / 13 / 1$ & $3 / 17 / 0$ \\
Body mass index & $25.7 \pm 3.4$ & $24.2 \pm 3.8$ \\
Duration of surgery $(\mathrm{h})$ & $3.0 \pm 0.7$ & $2.8 \pm 0.5$ \\
Duration of anesthesia $(\mathrm{h})$ & $3.7 \pm 0.7$ & $3.6 \pm 0.5$ \\
Infusion rate of remifentanil $(\mu \mathrm{g} / \mathrm{kg} / \mathrm{h})$ & $2.3 \pm 1.5$ & $1.7 \pm 1.1$ \\
\hline
\end{tabular}

Values are mean \pm SD or absolute number. No statistically significant differences were noted between the groups.

Table 2. Mean Infusion Rate of Fentanyl

\begin{tabular}{lcc}
\hline & $\begin{array}{c}\text { Control } \\
(\mathrm{n}=20)\end{array}$ & $\begin{array}{c}\text { Ketamine } \\
(\mathrm{n}=20)\end{array}$ \\
\hline 1 h after surgery & $1.4 \pm 0.6$ & $1.5 \pm 0.5$ \\
1 h till 24 h after surgery & $0.6 \pm 0.5$ & $0.6 \pm 0.2$ \\
24 h till 48 h after surgery & $0.6 \pm 0.2$ & $0.5 \pm 0.1$ \\
\hline
\end{tabular}

Values are mean \pm SD. Units of infusion rate: $\mu \mathrm{g} / \mathrm{kg} / \mathrm{hr}$. No statistically significant differences were noted between the groups.
Mann-Whitney test, and other factors of patients' parametric data (age, weight, height, BMI, and duration of surgery and anesthesia) and infusion rates were compared using an unpaired t-test. Results are expressed as the mean \pm SD unless otherwise specified. A probability (P) value of less than 0.05 was considered to be statistically significant.

\section{Results}

There were no statistical differences in patient demographics, the duration of surgery and anesthesia or intra-operative remifentanil administration (Table 1). We did not find any significant difference in postoperative PCA fentanyl requirements (Table 2)

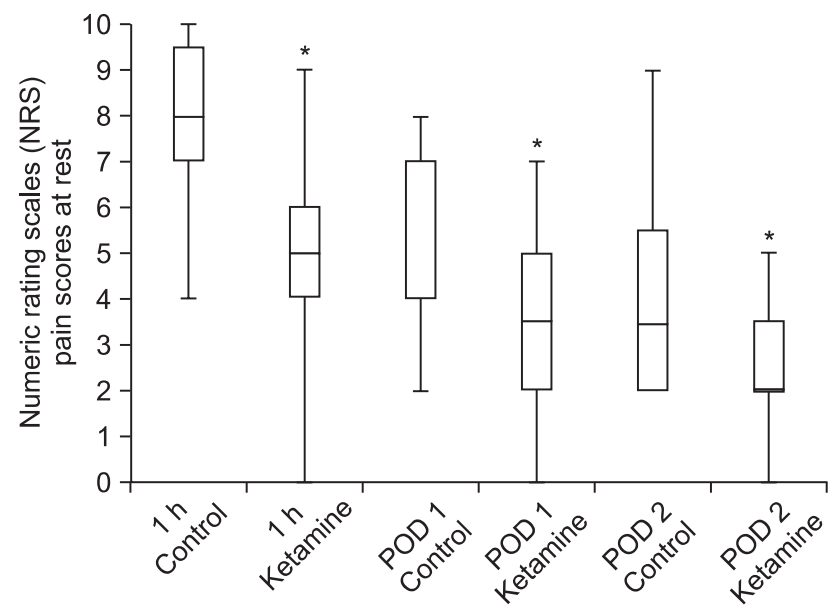

Fig. 1. Numerical Rating Scale (NRS) at Rest. Box and whisker plot show the numeric rating scale (NRS) pain scores at rest. POD: postoperative day. $* \mathrm{P}<0.05$ versus the control group.

Table 4. Numerical Rating Scale (NRS) at Rest

\begin{tabular}{lcc}
\hline & $\begin{array}{c}\text { Control } \\
(\mathrm{n}=20)\end{array}$ & $\begin{array}{c}\text { Ketamine } \\
(\mathrm{n}=20)\end{array}$ \\
\hline $1 \mathrm{~h}$ in PACU & $8.2 \pm 1.5$ & $5.1 \pm 2.0^{*}$ \\
POD 1 & $5.1 \pm 2.1$ & $3.6 \pm 2.0^{*}$ \\
POD 2 & $4.2 \pm 2.1$ & $2.4 \pm 1.4^{*}$ \\
\hline
\end{tabular}

Values are mean \pm SD. A NRS of 0 was defined as no pain and 10 was defined as the worst pain ever experienced. PACU: post-anesthesia care unit, POD: postoperative day. ${ }^{*} \mathrm{P}<0.05$ versus the control group.

Table 3. Incidence of Side Effects Observed in this Study

\begin{tabular}{|c|c|c|c|c|c|c|}
\hline & \multicolumn{3}{|c|}{ Control $(n=20)$} & \multicolumn{3}{|c|}{ Ketamine $(n=20)$} \\
\hline & $\mathrm{N} / \mathrm{V}$ & Confusion & Hallucination & $\mathrm{N} / \mathrm{V}$ & Confusion & Hallucination \\
\hline $1 \mathrm{~h}$ in PACU & 2 & 0 & 0 & 1 & 0 & 0 \\
\hline POD 1 & 3 & 0 & 0 & 3 & 0 & 0 \\
\hline POD 2 & 4 & 0 & 0 & 1 & 0 & 0 \\
\hline
\end{tabular}

No statistically significant differences were noted between the groups. N/V: nausea/vomiting, PACU: post-anesthesia care unit, POD: postoperative day. 
or side effects (Table 3 ) between the groups. However, we found a significant difference in NRS between the two groups (Table 4 and Fig. 1).

\section{Discussion}

Opioids are traditionally used as part of general anesthesia and postoperatively for acute pain control. The administration of large doses of narcotics in the perioperative period can have multiple side effects including respiration depression, sedation, nausea and vomiting, pruritus, urinary retention, ileus, and delayed hospital discharge [10] . It is for these reasons as well as the modulation of pain perception as a complex process involving multiple neural pathways, that many clinicians now advocate a multimodal therapeutic approach (balanced analgesia) for the management of pain [1] .

Balanced analgesia consists of the administration of several analgesic drugs that act on different systems to alleviate postoperative pain. A combination of drugs allows adequate analgesia with a low dose of each component and decreases the incidence of side effects. Opiates, NSAIDs, and ketamine are currently used for balanced analgesia although the role of ketamine remains controversial [5-9] .

As a component of balanced analgesia, NSAIDs can reduce the incidence of side effects and postoperative opioid requirement $[2,11,12]$. However, because NSAIDs may have a negative influence on the success of spinal fusions, some surgeons do not recommend the use of NSAIDs for acute postoperative pain control [2-4] .

Ketamine, a noncompetitive $N$-methyl $D$-aspartate (NMDA) receptor blocker [13], is a potent analgesic and can be used at a low dose as a sole or adjuvant agent for postoperative pain control. The blocking effect of ketamine in the processing of nociceptive inputs has led to its use in the treatment of chronic pain syndromes [14] and neuropathic pain [15]. Also, perioperative ketamine may be useful for patients who require larger doses of opioids, such as cancer patients or narcotictolerant patients [10], patients who are especially sensitive to the adverse effects of opioids such as the elderly, and patients who should avoid the use of NSAIDs due to a prior history of gastrointestinal bleeding or reflux, coagulopathy, allergy to NSAIDs and concurrent steroid use.

Acute opioid tolerance may be associated with opioids used during surgery. Studies suggest that high but not low intraoperative opioid dose is associated with increased pain and/or opioid requirement after surgery [16-18] . In our study we were not able to verify if low dose ketamine could prevent the development of acute opioid tolerance, because the dose of remifentanil we used intraoperatively $(2.3 \pm 1.5 \mu \mathrm{g} / \mathrm{kg} / \mathrm{hr}$ in the control group and $1.7 \pm 1.1 \mu \mathrm{g} / \mathrm{kg} / \mathrm{hr}$ in ketamine group) was low, which is not supposed to produce acute tolerance based on previous studies [19-21]. Therefore, it is unlikely that acute tolerance developed and the low dose ketamine we used had a preventative effect.

At low, sub-dissociative doses, ketamine has been found to be useful in the management of acute pain in some studies $[9,22]$, but not in others [23]. A dose of $2.0 \mu \mathrm{g} / \mathrm{kg} / \mathrm{h}$ of ketamine reduced postoperative pain in narcotic-tolerant patients undergoing posterior spine fusion during the first postoperative hour in the PACU and the first postoperative day at rest [10]. The Cochrane review of ketamine (different practice regarding dose, route and time of administration) for postoperative pain, reported that in 27 of 37 reviewed trials, ketamine reduced opioid analgesic requirements, or pain intensity, or both [24]. Four of these trials included fixed continuous infusion rates of ketamine (1.0$2.5 \mu \mathrm{g} / \mathrm{kg} / \mathrm{min}$ ) intraoperatively and postoperatively, with and without an intravenous bolus of ketamine [25-28]. In these trials the ketamine group was compared to intravenous PCA morphine alone for pain scores and cumulative morphine administration. Three trials demonstrated that ketamine was morphine sparing [25-27]. Among the three trials, two demonstrated that the VAS pain scores were reduced only in the first 1 hour after surgery $[25,26]$ and the other trial showed that pain was not reduced at all [27]. It is not possible to compare the results of our study with previous ones because the methodologies are different. Previous studies have fixed the continuous infusion rate of ketamine regardless of patients' opioid requirement, however, in our study the dose of ketamine $(0.5-2.5 \mu \mathrm{g} / \mathrm{kg} / \mathrm{min})$ was proportional to that of fentanyl based on the patient's opioid requirement. Ketamine in our study did not have a fentanyl-sparing effect, but induced the reduction in NRS. Verifying the fentanyl-sparing effects of ketamine was difficult because the degree of pain sensed by the patients was moderate and PCA bolus and basal volume was equal.

Among the ketamine related adverse effects, the risk for hallucination is high in awake or sedated patients receiving ketamine without benzodiazepine, but low in patients undergoing general anesthesia and independent of benzodiazepine premedication [29]. Ketamine-related adverse effects are known to be mild or absent when the surgery is performed under general anesthesia [24]. In our study, all patients were under general anesthesia and none of them complained of hallucination or nightmares. We did not find any difference between the two groups.

The effects of ketamine on PONV are controversial. There are some studies suggesting that ketamine has no effect in decreasing the incidence of PONV [29]. On the other hand, there are some studies showing that ketamine has significantly reduced nausea and vomiting [8]. In our study, ramosetron was administered to all patients before wound closure, so there was 
no significant difference in PONV between the groups.

We conclude that the infusion of ketamine $(0.5-2.5 \mu \mathrm{g} / \mathrm{kg} /$ min) proportional to fentanyl dose is not only safe, but also reduces postoperative pain intensity in patients undergoing spinal fusion surgery although the fentanyl-sparing effects of ketamine were not demonstrated in this study. Therefore, the postoperative infusion of ketamine proportional to fentanyl dose may be a useful adjuvant to postoperative balanced analgesic management as an alternative substitute of NSAIDs to manage acute postoperative pain after spinal fusion.

\section{References}

1. Kehlet H, Werner M, Perkins F. Balanced analgesia: what is it and what are its advantages in postoperative pain? Drugs 1999; 58: 7937.

2. Park SY, Moon SH, Park MS, Oh KS, Lee HM. The effects of ketorolac injected via patient controlled analgesia postoperatively on spinal fusion. Yonsei Med J 2005; 46: 245-51.

3. Glassman SD, Rose SM, Dimar JR, Puno RM, Campbell MJ, Johnson JR. The effect of postoperative nonsteroidal anti-inflammatory drug administration on spinal fusion. Spine (Phila Pa 1976) 1998; 23: 834-8.

4. Li Q, Zhang Z, Cai Z. High-dose ketorolac affects adult spinal fusion: a meta-analysis of the effect of perioperative nonsteroidal anti-inflammatory drugs on spinal fusion. Spine (Phila Pa 1976) 2011; 36: E461-8.

5. Dahl V, Ernoe PE, Steen T, Raeder JC, White PF. Does ketamine have preemptive effects in women undergoing abdominal hysterectomy procedures? Anesth Analg 2000; 90: 1419-22.

6. Mathisen LC, Aasbo V, Raeder J. Lack of pre-emptive analgesic effect of (R)-ketamine in laparoscopic cholecystectomy. Acta Anaesthesiol Scand 1999; 43: 220-4.

7. Kwok RF, Lim J, Chan MT, Gin T, Chiu WK. Preoperative ketamine improves postoperative analgesia after gynecologic laparoscopic surgery. Anesth Analg 2004; 98: 1044-9.

8. Schmid RL, Sandler AN, Katz J. Use and efficacy of low-dose ketamine in the management of acute postoperative pain: a review of current techniques and outcomes. Pain 1999; 82: 111-25.

9. Javery KB, Ussery TW, Steger HG, Colclough GW. Comparison of morphine and morphine with ketamine for postoperative analgesia. Can J Anaesth 1996; 43: 212-5.

10. Urban MK, Ya Deau JT, Wukovits B, Lipnitsky JY. Ketamine as an adjunct to postoperative pain management in opioid tolerant patients after spinal fusions: a prospective randomized trial. HSS J 2008; 4: 62-5.

11. Chen JY, Wu GJ, Mok MS, Chou YH, Sun WZ, Chen PL, et al. Effect of adding ketorolac to intravenous morphine patient-controlled analgesia on bowel function in colorectal surgery patients--a prospective, randomized, double-blind study. Acta Anaesthesiol Scand 2005; 49: 546-51.

12. Sutters KA, Shaw BA, Gerardi JA, Hebert D. Comparison of morphine patient-controlled analgesia with and without ketorolac for postoperative analgesia in pediatric orthopedic surgery. Am J Orthop (Belle Mead NJ) 1999; 28: 351-8.
13. Kohrs R, Durieux ME. Ketamine: teaching an old drug new tricks. Anesth Analg 1998; 87: 1186-93.

14. Hocking G, Cousins MJ. Ketamine in chronic pain management: an evidence-based review. Anesth Analg 2003; 97: 1730-9.

15. Zhou HY, Chen SR, Pan HL. Targeting N-methyl-D-aspartate receptors for treatment of neuropathic pain. Expert Rev Clin Pharmacol 2011; 4: 379-88.

16. Chia YY, Liu K, Wang JJ, Kuo MC, Ho ST. Intraoperative high dose fentanyl induces postoperative fentanyl tolerance. Can J Anaesth 1999; 46: 872-7.

17. Guignard B, Bossard AE, Coste C, Sessler DI, Lebrault C, Alfonsi P, et al. Acute opioid tolerance: intraoperative remifentanil increases postoperative pain and morphine requirement. Anesthesiology 2000; 93: 409-17.

18. Joly V, Richebe P, Guignard B, Fletcher D, Maurette P, Sessler DI, et al. Remifentanil-induced postoperative hyperalgesia and its prevention with small-dose ketamine. Anesthesiology 2005; 103: 147-55.

19. Cortinez LI, Brandes V, Munoz HR, Guerrero ME, Mur M. No clinical evidence of acute opioid tolerance after remifentanil-based anaesthesia. Br J Anaesth 2001; 87: 866-9.

20. Gustorff B, Nahlik G, Hoerauf KH, Kress HG. The absence of acute tolerance during remifentanil infusion in volunteers. Anesth Analg 2002; 94: 1223-8.

21. Jaksch W, Lang S, Reichhalter R, Raab G, Dann K, Fitzal S. Perioperative small-dose $\mathrm{S}(+)$-ketamine has no incremental beneficial effects on postoperative pain when standard-practice opioid infusions are used. Anesth Analg 2002; 94: 981-6.

22. De Kock M, Lavand'homme P, Waterloos H. 'Balanced analgesia' in the perioperative period: is there a place for ketamine? Pain 2001; 92: 373-80

23. Edwards ND, Fletcher A, Cole JR, Peacock JE. Combined infusions of morphine and ketamine for postoperative pain in elderly patients. Anaesthesia 1993; 48: 124-7.

24. Bell RF, Dahl JB, Moore RA, Kalso E. Peri-operative ketamine for acute post-operative pain: a quantitative and qualitative systematic review (Cochrane review). Acta Anaesthesiol Scand 2005; 49: 140528.

25. Stubhaug A, Breivik H, Eide PK, Kreunen M, Foss A. Mapping of punctuate hyperalgesia around a surgical incision demonstrates that ketamine is a powerful suppressor of central sensitization to pain following surgery. Acta Anaesthesiol Scand 1997; 41: 1124-32.

26. Adriaenssens G, Vermeyen KM, Hoffmann VL, Mertens E, Adriaensen HF. Postoperative analgesia with i.v. Patient-controlled morphine: effect of adding ketamine. Br J Anaesth 1999; 83: 393-6.

27. Guillou N, Tanguy M, Seguin P, Branger B, Campion JP, Malledant $\mathrm{Y}$. The effects of small-dose ketamine on morphine consumption in surgical intensive care unit patients after major abdominal surgery. Anesth Analg 2003; 97: 843-7.

28. Ilkjaer S, Nikolajsen L, Hansen TM, Wernberg M, Brennum J, Dahl JB. Effect of i.v. ketamine in combination with epidural bupivacaine or epidural morphine on postoperative pain and wound tenderness after renal surgery. Br J Anaesth 1998; 81: 707-12.

29. Elia N, Tramer MR. Ketamine and postoperative pain--a quantitative systematic review of randomised trials. Pain 2005; 113: 61-70. 